\title{
Report on test methods and recommendations
}

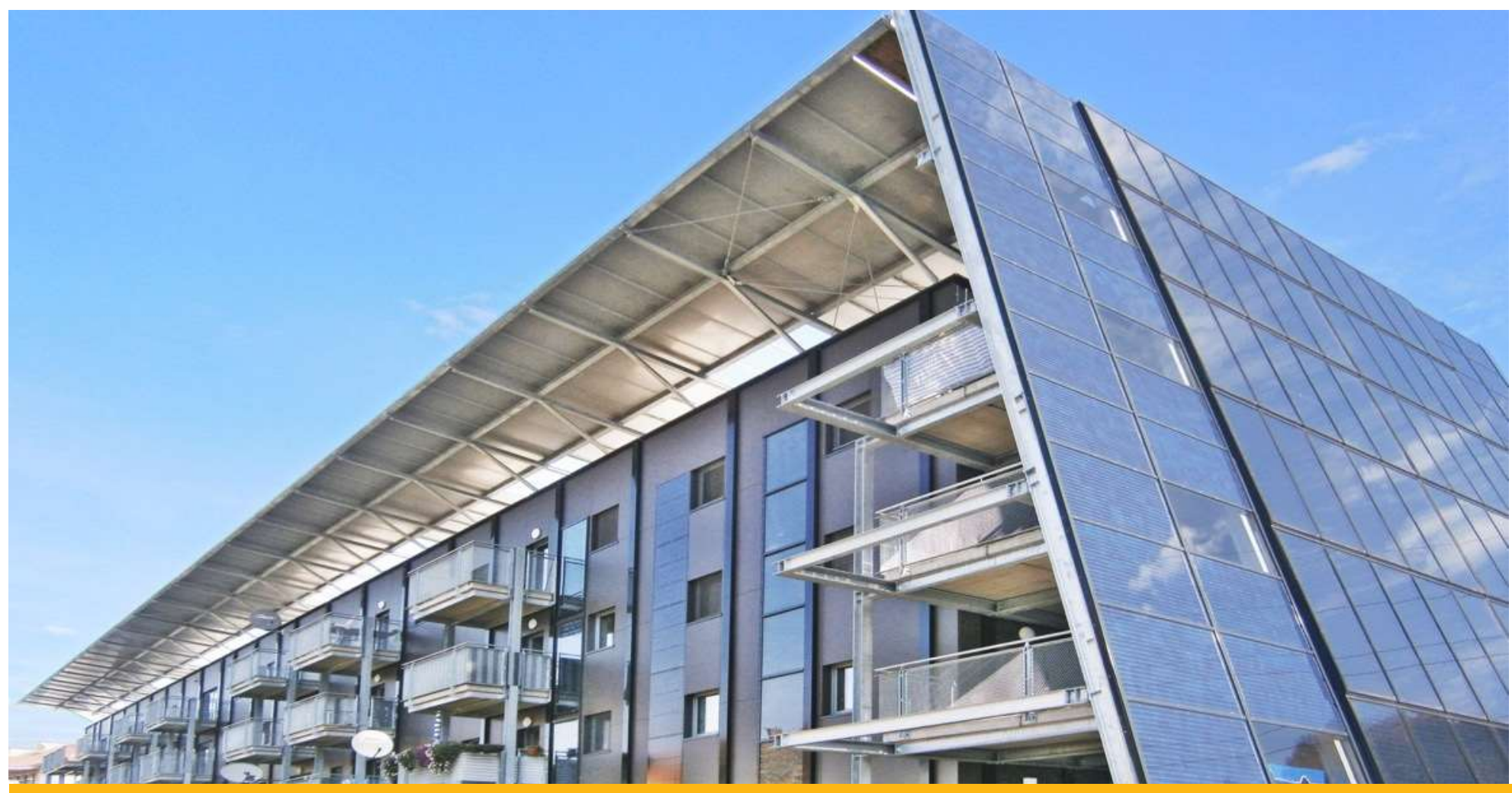

IEA SHC TASK 56 | Building Integrated Solar Envelope Systems for HVAC and Lighting 


\section{Report on test methods and recommendations}

\section{Deliverable DB.5}

Editor: Christoph Maurer (Fraunhofer ISE)

Authors (in alphabetical order):

Bruno Bueno (Fraunhofer ISE)

Carolin Hubschneider (Fraunhofer IBP)

Christoph Maurer (Fraunhofer ISE)

David Geisler-Moroder (Bartenbach)

David Venus (AEE INTEC)

Fabian Ochs (University of Innsbruck)

Michaela Meir (Aventa)

Noel O'Neill (DIT)

Paolo Bonato (Eurac Research)

Philippe Lemarchand (DIT)

Tilmann E. Kuhn (Fraunhofer ISE)

Vickie Aagesen (Cenergia, part of Kuben Management)

\section{April, 2020}

DB.5, DOI: 10.18777/ieashc-task56-2020-0003

The contents of this report do not necessarily reflect the viewpoints or policies of the International Energy Agency (IEA) or its member countries, the IEA Solar Heating and Cooling Technology Collaboration Programme (SHC TCP) members or the participating researchers. 


\section{IEA Solar Heating and Cooling Technology Collaboration Programme (IEA SHC)}

The Solar Heating and Cooling Technology Collaboration Programme was founded in 1977 as one of the first multilateral technology initiatives ("Implementing Agreements") of the International Energy Agency. Its mission is "To enhance collective knowledge and application of solar heating and cooling through international collaboration to reach the goal set in the vision of solar thermal energy meeting $50 \%$ of low temperature heating and cooling demand by 2050."

The members of the IEA SHC collaborate on projects (referred to as Tasks) in the field of research, development, demonstration (RD\&D), and test methods for solar thermal energy and solar buildings.

Research topics and the associated Tasks in parenthesis include:

- $\quad$ Solar Space Heating and Water Heating (Tasks 14, 19, 26, 44, 54)

- Solar Cooling (Tasks 25, 38, 48, 53)

- Solar Heat for Industrial or Agricultural Processes (Tasks 29, 33, 49, 62, 64)

- Solar District Heating (Tasks 7, 45, 55)

- Solar Buildings/Architecture/Urban Planning (Tasks 8, 11, 12, 13, 20, 22, 23, 28, 37, 40, 41, 47, 51, 52, 56, $59,63)$

- $\quad$ Solar Thermal \& PV (Tasks 16, 35, 60)

- Daylighting/Lighting (Tasks 21, 31, 50,61)

- Materials/Components for Solar Heating and Cooling (Tasks 2, 3, 6, 10, 18, 27, 39)

- $\quad$ Standards, Certification, and Test Methods (Tasks 14, 24, 34, 43, 57)

- $\quad$ Resource Assessment (Tasks 1, 4, 5, 9, 17, 36, 46)

- $\quad$ Storage of Solar Heat (Tasks $7,32,42,58$ )

In addition to our Task work, other activities of the IEA SHC include our:

$>$ International Conference on Solar Heating and Cooling for Buildings and Industry

$>$ SHC Solar Academy

$>$ Solar Heat Worldwide annual statics report

$>$ Collaboration with solar thermal trade associations

\section{Country Members}

Australia

Austria

Belgium

Canada

China

Denmark

European Commission

\section{Sponsor Members}

European Copper Institute International Solar Energy Society

EACREEE

$\begin{array}{ll}\text { France } & \text { South Africa } \\ \text { Germany } & \text { Spain } \\ \text { Italy } & \text { Sweden } \\ \text { Netherlands } & \text { Switzerland } \\ \text { Norway } & \text { Turkey } \\ \text { Portugal } & \text { United Kingdom }\end{array}$

ECREEE

RCREEE

SACREEE

For more information on the IEA SHC work, including many free publications, please visit www.iea-shc.org 


\section{Contents}

1 CONTENTS

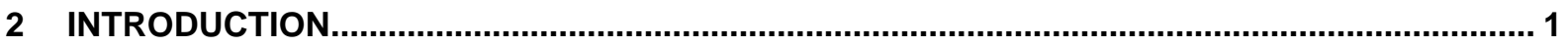

3 ANALYSIS OF STANDARDS

3.1 CE marking and Construction Products Regulation ........................................................ 2

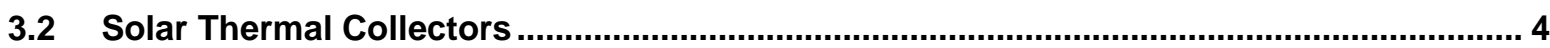

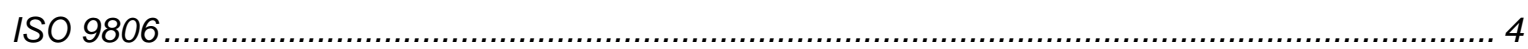

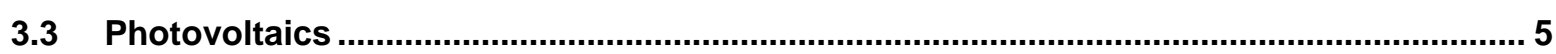

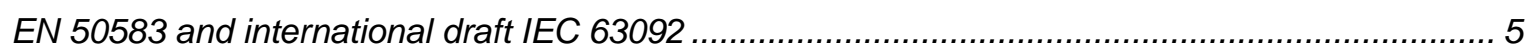

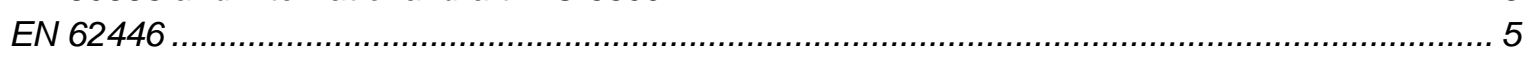

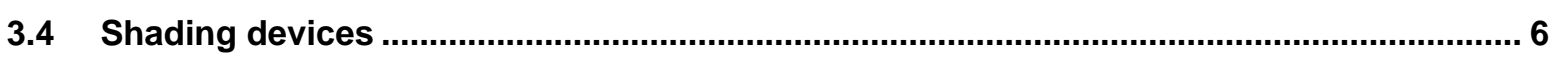

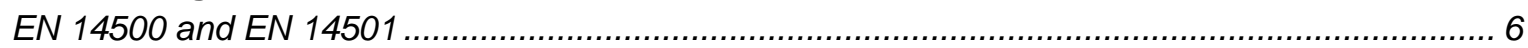

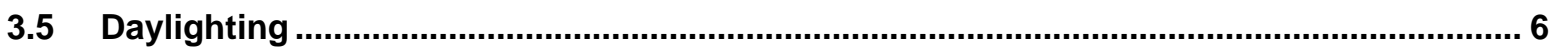

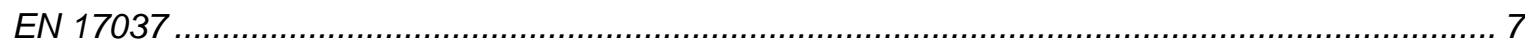

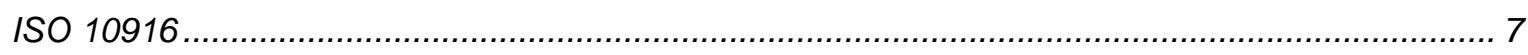

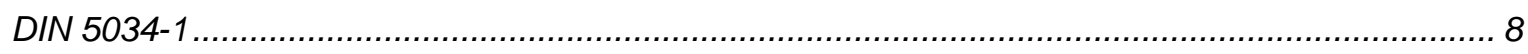

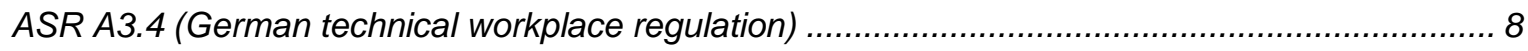

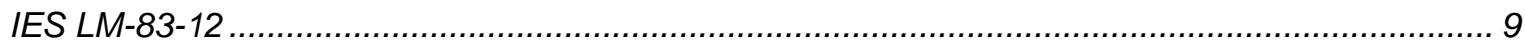

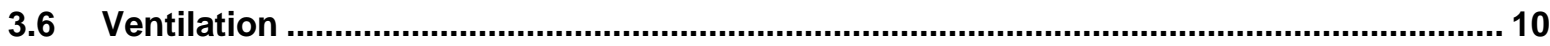

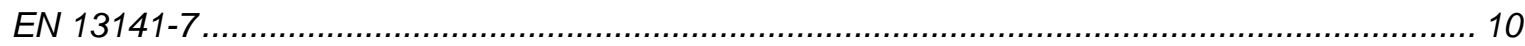

$3.7 \quad$ Heat Pumps

EN 14511-2

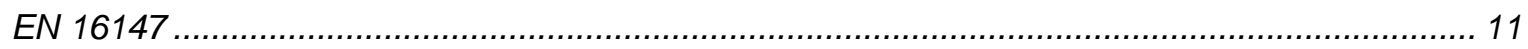

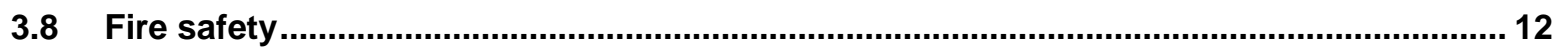

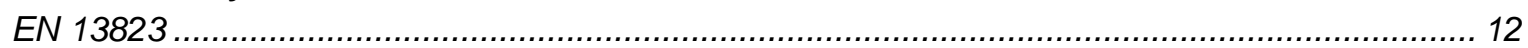

ISO 11925-2

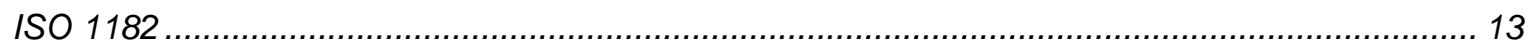

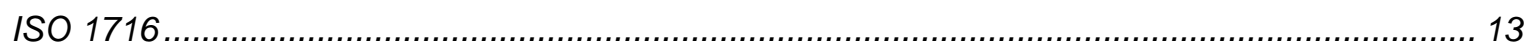

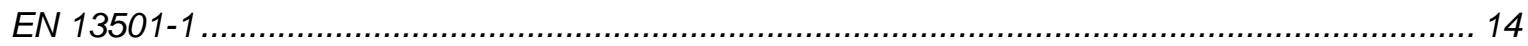

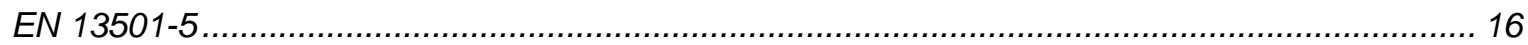

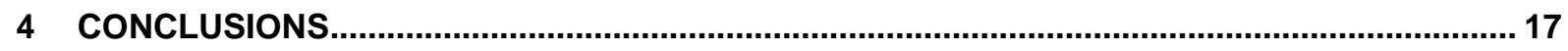

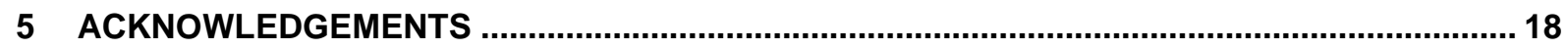

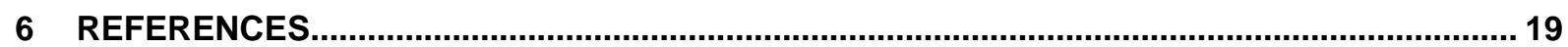




\section{Introduction}

Standards are evidence based on science, technology and practice. Test standards are rating procedures designed to give consistent outcomes. They are based on compliance organized and approved by a legally or consensually recognized body. They provide requirements, procedures and guidelines for testing design, installation, use and disposal. Standards aim to achieve component/system interoperability, satisfy legislation and facilitate healthy and safety. Standards can be an effective instrument for addressing energy efficiency in buildings to support the achievement of decarbonisation targets when there is effective enforcement through compliance checks, incentives and other supporting instruments. Building energy codes, also known in some countries as "energy standards for buildings", "thermal building regulations", "energy conservation building codes" or "energy efficiency building codes" are a policy instrument used by governments to limit energy use and greenhouse gas emissions from the built environment whilst ensuring occupant comfort. Building energy codes often stipulate desired energy efficiency characteristics for building by either prescribing minimum energy performance requirements for each building component or adopt a performance approach that requires a holistic assessment of building energy performance.

This report presents an analysis of current test methods that can be applied to Solar Building Envelope (SBE) technologies. It is the result of the work of international experts within Subtask B of IEA SHC Task 56. Relevant standards for construction products, solar thermal collectors, photovoltaics, daylighting systems, ventilation devices and heat pumps are selected and assessed. The selection includes the most important standards for fire protection as applied to SBE technologies. For each standard, the report assesses its applicability to SBE technologies. At the end, recommendations are presented on how current standards and regulations could be improved to prepare the ground for a wider adoption of SBE systems. 


\subsection{CE marking and Construction Products Regulation}

The CE marking procedure is a mandatory requirement for all products subject to specific harmonized European directives that provide clauses for CE marking and thus applies also to solar building integrated products in the CE market. With CE marking, the manufacturer declares the conformity of the product to the requisites foreseen by European directives through the Declaration of Conformity (DoC) or the Declaration of Performance (DoP) for construction products. In other words, the manufacturer declares that he has checked that the product satisfies all legislative requirements for the product to be placed on the market. For building-integrated components and systems, it might be required that the product is compliant with directives targeting both active components (e.g. Energy related Products directive, Low Voltage Directive) and the European regulation on construction products or CPR.

The Construction Products Regulation (Regulation EU No 305/2011) came into force on 1st July 2013 replacing the existing CPD Directive 89/106/EEC. The CPR targets construction products, defined as "product or kit which is produced and placed on the market for incorporation in a permanent manner in construction works or parts thereof and the performance of which has an effect on the performance of the construction works with respect to the basic requirements for construction works".

Nowadays, the harmonized European directives cover already a wide range of construction products, from lighting columns, to wires and pipes - and target also envelope components such as glass in buildings, self-supporting insulation panels or tiles. Construction products that are not covered -or fully covered- by these harmonized directives (e.g. innovative products) do not need to bear the CE mark, but can voluntarily affix the CE mark through an alternative route, which is the release of the European Technical Assessment or ETA. They are released by the Technical Assessment Bodies (or TABs) coherently with the respect of guidelines defined by the responsible European Organisation for Technical Approvals or EOTA. The legal basis for the ETA route is provided by the CPR regulation.

Based on the CPR regulation, construction products must satisfy one or more of the "essential requisites" listed in the table below.

\begin{tabular}{|c|c|}
\hline $\begin{array}{l}\text { Mechanical } \\
\text { resistance } \\
\text { and stability }\end{array}$ & $\begin{array}{l}\text { The construction works must be designed and built in such a way that the loadings that are } \\
\text { liable to act on them during their constructions and use will not lead to any of the following: } \\
\text { collapse of the whole or part of the work; } \\
\circ \text { major deformations to an inadmissible degree; } \\
\text { damage to other parts of the construction works or to fittings or installed equipment as } \\
\text { a result of major deformation of the load-bearing construction; } \\
\text { damage by an event to an extent disproportionate to the original cause. }\end{array}$ \\
\hline $\begin{array}{l}\text { Safety in } \\
\text { case of fire }\end{array}$ & $\begin{array}{l}\text { The construction works must be designed and built in such a way that in the event of an } \\
\text { outbreak of fire: } \\
\text { the load-bearing capacity of the construction can be assumed for a specific period of } \\
\text { time; } \\
\circ \text { the generation and spread of fire and smoke within the construction works are limited; } \\
\circ \text { the spread of fire to neighbouring construction works is limited; } \\
\circ \text { occupants can leave the construction works or be rescued by other means; } \\
\circ \text { the safety of rescue teams is taken into consideration. }\end{array}$ \\
\hline $\begin{array}{l}\text { Hygiene, } \\
\text { health and } \\
\text { the } \\
\text { environment }\end{array}$ & $\begin{array}{l}\text { The construction works must be designed and built in such a way that they will, throughout } \\
\text { their life cycle, not be a threat to the hygiene or health and safety of workers, occupants or } \\
\text { neighbours, nor have an exceedingly high impact, over their entire life cycle, on the } \\
\text { environmental quality or on the climate during their construction, use and demolition, in } \\
\text { particular as a result of any of the following: } \\
\text { o the giving-off of toxic gas; } \\
\text { the emissions of dangerous substances, volatile organic compounds (VOC), } \\
\text { greenhouse gases or dangerous particles into indoor or outdoor air; } \\
\text { the emission of dangerous radiation; } \\
\text { the release of dangerous substances into ground water, marine waters, surface } \\
\text { waters or soil; }\end{array}$ \\
\hline
\end{tabular}




\begin{tabular}{|c|c|}
\hline & $\begin{array}{l}\text { the release of dangerous substances into drinking water or substances which have an } \\
\text { otherwise negative impact on drinking water; } \\
\text { faulty discharge of waste water, emission of flue gases or faulty disposal of solid or } \\
\text { liquid waste; } \\
\text { dampness in parts of the construction works or on surfaces within the construction } \\
\text { works. }\end{array}$ \\
\hline $\begin{array}{l}\text { Safety and } \\
\text { accessibility } \\
\text { in use }\end{array}$ & $\begin{array}{l}\text { The construction works must be designed and built in such a way that they do not present } \\
\text { unacceptable risks of accidents or damage in service or in operation such as slipping, falling, } \\
\text { collision, burns, electrocution, injury from explosion and burglaries. In particular, construction } \\
\text { works must be designed and built taking into consideration accessibility and use for disabled } \\
\text { persons. }\end{array}$ \\
\hline $\begin{array}{l}\text { Protection } \\
\text { against } \\
\text { noise }\end{array}$ & $\begin{array}{l}\text { The construction works must be designed and built in such a way that noise perceived by the } \\
\text { occupants or people nearby is kept to a level that will not threaten their health and will allow } \\
\text { them to sleep, rest and work in satisfactory conditions. }\end{array}$ \\
\hline $\begin{array}{l}\text { Energy } \\
\text { economy } \\
\text { and heat } \\
\text { retention }\end{array}$ & $\begin{array}{l}\text { The construction works and their heating, cooling, lighting and ventilation installations must } \\
\text { be designed and built in such a way that the amount of energy they require in use shall be } \\
\text { low, when account is taken of the occupants and of the climatic conditions of the location. } \\
\text { Construction works must also be energy-efficient, using as little energy as possible during } \\
\text { their construction and dismantling. }\end{array}$ \\
\hline $\begin{array}{l}\text { Sustainable } \\
\text { use of } \\
\text { natural } \\
\text { resources }\end{array}$ & $\begin{array}{l}\text { The construction works must be designed, built and demolished in such a way that the use of } \\
\text { natural resources is sustainable and in particular ensure the following: } \\
\text { reuse or recyclability of the construction works, their materials and parts after } \\
\text { demolition; } \\
\text { durability of the construction works; } \\
\text { use of environmentally compatible raw and secondary materials in the construction } \\
\text { works }\end{array}$ \\
\hline
\end{tabular}

All product standards include a section called "Annex ZA" that lists the essential characteristics relevant for the studied construction product. Such list can be different depending on the intended use of a product if there is more than one. Moreover, in order to guarantee the reliability and accuracy in time of the data reported in the Declaration of Performance, a system for the assessment and verification of performance (or AVCP) must be put in place. In Annex ZA, it is also clarified whether the assessment of the performances can be a "first-party assessment" or must be a "third party assessment" performed by a notified body.

The Construction Products Regulation recognizes a few exemptions to its application (Article 5 of CPR) and admits the use of simplified procedures (Articles 36 to 38 of CPR), as for example in the case of micro-enterprises or for the practices known as "Sharing ITT" and "Cascading ITT".

More information on the CE marking process of construction products can be found here: https://ec.europa.eu/growth/content/ce-marking-construction-products-step-step-guide-now-available-all-eulanguages-0_en 


\subsection{Solar Thermal Collectors}

\section{ISO 9806}

\section{Short description of the standard}

ISO 9806 describes the methods on how solar thermal collectors can be tested regarding their solar thermal performance, their durability and safety. While ISO 9806 does not include labelling, other standards and regulations like EN 12975-1 and the Solar Keymark Label can refer to ISO 9806 and its methods.

\section{Analysis of the standard}

If a manufacturer produces a "family of solar thermal collectors", with many different lengths and widths, it can get a Solar Keymark Label for this collector family. However, regulations in a European country may require that each collector size needs to be tested separately ${ }^{1}$, which is a major barrier for manufacturers of solar building envelopes (SBE) where project specific dimensions are frequent.

Another challenge is that test laboratories are used to measure typical collector dimensions, e.g. $2.1 \times 1.1 \mathrm{~m}^{2}$. However, SBE elements can be much larger. Of course, it is possible to build an SBE element with the dimensions of a typical solar thermal collector. However, this leads to increased edge losses compared to the large elements. Measurements on solar thermal building envelopes have shown that calculations based on small dimensions significantly underestimate the performance of large elements.

A similar challenge occurs with the mechanical tests for wind and snow loads. Test facilities typically measure horizontal samples, although the original mounting position is required by the standard. There are SBE that behave differently whether they are vertical or horizontal. In that case, appropriate test facilities are needed which may not be available yet.

The above mentioned standards and regulations were developed for solar thermal collectors to be added to the building envelope with rear-ventilation. Therefore, the equations for the solar thermal performance include the temperatures of the fluid and of the ambient, but not of the building interior. Building-integrated solar thermal (BIST) elements typically exchange heat with the building interior, loosing then less heat in this way than rear-ventilated solar thermal flat-plate collectors. When the equations of typical solar thermal collectors are used for BIST, the solar thermal performance is typically underestimated.

Building construction processes require the calculation of the heating demand of the building. For BIST elements, there is no standard to quantify the heat exchange with the building as a basis to calculate the heating demand. This prevents BIST technologies to profit from energy savings incentives. Regulations should be developed to account for these benefits [1].

Finally, BIST technologies can be installed in countless configurations where, especially the thermal resistance between the solar thermal absorber and the building interior varies. This affects the solar thermal performance as well as the heat exchange with the building interior. Standards and regulations need to develop methods in order to easily predict the performances of BIST installations based on as few measurements as possible.

\footnotetext{
${ }^{1}$ Investigated during early 2016
} 


\subsection{Photovoltaics}

\section{EN 50583 and international draft IEC 63092}

\section{Short description of the standard}

The aim of the new European and international BIPV standards is to provide an overview of the various other standards and requirements from different sectors that must be taken into account when manufacturing BIPV components or when installing BIPV systems on buildings. Both standards are two-part standards with a first part dealing with the module and a second part dealing with the system. They start by providing a typology of installation situations and then listing the other relevant standards from the electrical and construction sector to be respected for the different installation situations. This means that they do not contain very much "own" content. They are in the main part "guidance documents".

\section{Analysis of the standard}

The actual draft of the international standard is based on the valid European standard EN 50583. Relevant prenormative work for the upcoming international standard is done in the IEA PVPS task 15, in subtask C. The international standard will contain additional information such as the dependence of the g-value on solar electricity generation. The rest of this analysis is limited to the valid European Standard EN 50583.

The EN standard specifically addresses the properties of photovoltaic modules that are essential to meet basic building requirements. These are defined for Europe in the European Construction Products Directive CPD 89/106/EEC and the Low Voltage Directive 2006/95/EEC or in CENELEC standards for electrical products. The standard only refers to European or international standards and directives. For use in a specific installation situation on a building (e.g. as a safety barrier), additional national standards (or regulations) may apply in some countries for which no applicable harmonized European standards are (yet) available.

\section{EN 62446}

\section{Short description of the standard}

The aim of the standard is to highlight which kind of tests needs to be done in order to document that the installed photovoltaic system work properly on the electrical side. The listed demands for testing and documentation are for photovoltaic systems that are connected to the grid. The idea is that the building owner can refer to the demands in his tender or use the templates, which are also included in the standard, to make sure that the photovoltaic plant is working properly.

\section{Analysis of the standard}

The standard gives a good insight in the electrical aspect of what needs to be monitored when testing the photovoltaics in a plant. If the photovoltaic plant is performing lower than expected, the tests can be used to locate the week spot of a photovoltaic plant (except when the week spot is in the inverter).

When writing a tender, it is normally listed that the contractor should include in his offer a guaranteed performance, as well as an extern consultant, which is in charge of making a certain number of samples of the photovoltaics in the plant. When descripting the demands for the samples, there is a reference to the standard. However, in general, it is in the interest of the contractor that no weak spots, which would result in a lower performance, are reported for the photovoltaic plant. 


\subsection{Shading devices}

\section{EN 14500 and EN 14501}

\section{Short description of the standard}

EN 14500 defines test and calculation methods for the determination of the reflection and transmission characteristics to be used to determine the thermal and visual comfort performance classes of external blinds, internal blinds and shutters. It also specifies the method to determine opacity characteristics of dim-out/black-out systems. Products using a significant amount of fluorescent or retro-reflecting materials are outside the scope of this European Standard.

EN 14501 states the properties that shall be taken into account when comparing products. Examples are the Uvalue, the SHGC or g-value, as well as the normal-normal, normal-diffuse and normal-hemispherical transmittance and reflectance. Depending on predefined ranges of these properties, the Standard classifies fenestration components. The following aspects are taken into account:

- for the thermal comfort:
- the solar factor (total solar energy transmittance);
- the secondary heat transfer factor;
- the direct solar transmittance;

- for the visual comfort:

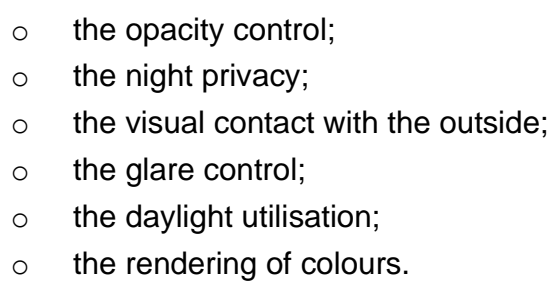

\section{Analysis of the standard}

The EN 14500 and EN 14501 standards have recently undergone an exhaustive revision, which at the beginning of 2020 is about to be completed. The test methods reported in EN 14500, which are mainly based on integrated spheres, have been more thoughtfully described to prevent discrepancies among characterization labs. A new experimental method will be proposed for the determination of normal-normal transmittance.

The EN 14501 provides a very simple and effective method to classify and compare products in terms of competing aspects such as daylight, glare protection, view contact with the outside and solar heat gains. The main problem of the standard is that it classifies fenestration products depending on their properties at normal incidence. Like this, angular selective fenestration products are disadvantaged. These products have higher transmittances for lower altitude angles, allowing view contact with the outside, and lower transmittances for higher altitude angles, effectively blocking solar heat gains and glare. This multifunctional performance is not rewarded by the current version of the standard. In the new version, a better classification of the fenestration product can be achieved if manufacturers can prove a lower cut-off angle (the incident angle from which the direct-direct transmittance is negligible). This measure can partially mitigate the problem.

\subsection{Daylighting}

There is ample evidence that provision of daylight in buildings makes a positive difference to occupants [2]. Daylighting has been defined by glazing area relative to room area; daylight factor in a room or sunlight duration for a specific day or season; and unshaded rights access to daylight. Actual daylight inside a room depends on building overhangs, shading and glass transmittance. Satisfaction of the visual comfort of occupants from daylight is represented by illuminance on a work-plane or by daylight factor. Standards involving daylight usually seek to define (i) design illuminance that enable people to perform visual tasks efficiently and accurately, (ii) conditions that ensure windows do not cause visual or thermal discomfort, or loss of privacy and (iii) energy savings by using daylight. As the magnitude and timing of the daylight provided by cloudy sky is stochastic, a standard cannot provide daylight illuminance at a given place and time; rather, from long-time data, the illuminance at a particular time and place will have a probability of lying within specific limits. 


\section{EN 17037}

\section{Short description of the standard}

The European standard EN 17037 "Daylight in buildings" describes criteria and calculation methods for the assessment of daylight in interior spaces.

The standard EN 17037 covers four main aspects of indoor lighting by natural light:

- Daylight provision:

According to the standard, adequate daylighting in a room can be considered if target illuminance levels and minimum illuminance levels are achieved across a fraction of the reference plane and across the overall reference plane, respectively. This should be true for at least half of the day lit hours. The calculation of the daylight provision is suggested using target daylight factors or using annual calculations based on climate data sets.

- Assessment of view out:

Occupants of a space should be able to visually connect to the outside of a building. For the assessment of the view out the standard defines three distinct layers: (i) sky, (ii) landscape, and (iii) ground. The quality of the view then depends on the geometry, i.e. area and view angle of the openings, the information in the view, and the outside distance of view.

- Exposure to sunlight:

Exposure to sunlight is seen as a quality criterion for daylighting and should be available in at least one habitable space in dwellings. The evaluation is done for a given reference day where reference points should receive direct sunlight for a predefined number of hours.

- Protection from glare:

Bright areas and high luminance can lead to visual discomfort and glare sensations which have to be avoided. The standard suggests using shading devices in any space with daylight openings and avoiding direct views to the sun or sun reflections. The Daylight Glare Probability (DGP) is suggested as criterion to assess potential glare for vertical or inclined windows.

\section{Analysis of the standard}

The EN 17037 provides suggestions for the evaluation of four main daylighting criteria "daylight provision", "view out", "sunlight exposure" and "glare protection". It is a first Europe-wide attempt to harmonize criteria and regulation for daylight in buildings.

Recommendations for target values and thresholds are given in Annex A of the standard, which is only of informative nature. The same is true for the calculation and verification methods which are specified in Annex $B$ (daylight provision), Annex C (view out), Annex D (exposure to sunlight), and Annex E (glare protection). This might lead to uncertainties and wrong interpretations in the application of the standard in the practical work.

The recommendations provided in Annex $A$ are all given for three levels: minimum, medium and high. This allows for efficient application of the standard for different settings and project requirements.

For all four aspects of daylighting, different methods (simplified - advanced or software - manual) for evaluation or verification are provided. This leads to the undesirable situation that the evaluation of same space can lead to different results and to different classifications of the lighting situation.

SBEs are only affected by this standard if they transmit light and thus contribute to indoor daylighting. As part of the transparent façade they are then required to perform within the area of conflict between daylight provision, glare and sun protection, and visual contact to the exterior. For new SBEs the standard provides a basic framework of daylighting related topics to be considered from the beginning of their development.

\section{ISO 10916}

\section{Short description of the standard}

The standard contents the calculation methodology for the monthly and annual amount of usable daylight for nonresidential buildings. This determines together with the characteristic values of the electric lighting systems the final energy demand for lighting. Several façade relating factors are considered in the methodology. 


\section{Analysis of the standard}

The structure (dimensions and materials) of the façade has an impact on the amount of usable daylight in nonresidential buildings.

For the calculation according to ISO 10916, the area of the building is divided into a daylight-lit area and an area which is not illuminated by daylight. This has finally an influence on the area that has to be illuminated only by electric and therewith the energy consumption of the building. The share of the two areas is depending on the size and the position of the window.

The daylight supply of the daylight-lit area varies with the obstruction index, which contents among others the influence of overhang and side shading. Constructions like glazed double facades are also taken into account. As further influencing factors the daylight supply is also depending on the transmittance of glazing and the type of sun shading (like glare protection only or light-guiding systems).

Future SBEs could content technical devices that lead to overhang and side shading (like non vertical PV) or include special glazing that reduce the transparency of the façade. So the installation of new SBEs can reduce the daylight supply, which increases the energy consumption for electric light. With the knowledge of the characteristic values (e.g. transmission) and the dimensions of the SBE, the ISO10916 can be applied to current and probably also to future SBEs.

\section{DIN 5034-1}

\section{Short description of the standard}

The German DIN 5034-1 "Daylight in interiors - Part 1: General requirements" deals with the daylight requirements for interiors. The aim is to guarantee sufficient brightness impression of daylight and view to the outside for working areas. Therefore several requirements for daylight openings and planning instructions are given.

\section{Analysis of the standard}

For sufficient daylight supply in the interior, daylight openings in the façade are in most cases mandatory. The DIN 5034-1 provides requirements for daylight openings which, to a certain extent, lead to some limitations for SBEs.

In order to provide a sufficient view to the outside rooms should be equipped with transparent, distortion-free and as far as possible colour-neutral glazed windows.

Because of the big influence of the window size on the daylight supply of the interior, the DIN 5034-1 gives minimum dimensions for daylight openings. Minimum width, height and share of the transparent part of the window are determined. The position of the window also influences the view to the outside and the daylight supply and is therefore given in the standard. To guarantee a sufficient daylight supply a minimum daylight factor is also required.

As a protection against glare, blinds or other systems have to be installed. Individually adjustable systems are recommended.

SBEs have to fit to the current standards. In case of DIN 5034-1 that means that the position of the SBE and the share of the façade that could be equipped are restricted in order to maintain a sufficient daylight supply. The need of glare protection has to be taken into account.

\section{ASR A3.4 (German technical workplace regulation)}

\section{Short description of the regulation}

The aim of German technical workplace regulation ASR A3.4 is to provide healthy conditions at the workplace. For different activities the necessary lighting conditions for working on visual tasks are determined. The regulation deals with daylight and electric light.

\section{Analysis of the regulation}

According to the regulation daylight has a positive effect on the well-being of occupants. Because of that a minimum daylight factor and a minimum ratio between transparent parts of windows /skylights and floor is given. Additionally the glazing that is used for the façade should lead to changes in the colour impression that are as small as possible. The regulation also requires glare reduction with blinds or other solutions. 
Regarding new SBE technology the ASR A3.4 (similar to the DIN 5034-1) restricts the size of systems and ensures that a sufficient glare protection is installed.

\section{IES LM-83-12}

\section{Short description of the standard}

The standard IES LM-83-12 "Approved Method: IES Spatial Daylight Autonomy (sDA) and Annual Sunlight Exposure (ASE)" describes two metrics and corresponding calculation methods for the assessment of day lit buildings.

- $\quad$ Spatial Daylight Autonomy (sDA):

The sDA is a metric to evaluate the daylight sufficiency in spaces. It is defined as percentage of analysis area on which a minimum illuminance level from daylight is achieved for a predefined percentage of working hours. If available, blinds or shades should be included in the evaluation.

$3001 x$ on horizontal surfaces and $50 \%$ of the working hours from $8 \mathrm{am}$ to $6 \mathrm{pm}$ are provided as the standard thresholds for the analysis. The standard further gives recommended sDA performance criteria with "preferred daylight sufficiency" for $\mathrm{sDA}_{3001 \times / 50 \%} \geq 75 \%$ and "nominally accepted daylight sufficiency" for $\mathrm{sDA}_{3001 \times / 50 \%} \geq 55 \%$.

- $\quad$ Annual Sunlight Exposure (ASE):

The ASE is a metric to evaluate the potential for visual discomfort in spaces. It is defined as percentage of analysis area on which a predefined illuminance level from direct sun is exceeded for a predefined number of working hours. Possible blinds or shades are not included in this evaluation.

$10001 x$ of direct sunlight and 250 working hours between $8 \mathrm{am}$ to $6 \mathrm{pm}$ are provided as the standard thresholds for the analysis. The standard only recommends that "a smaller sunlit area specified by the ASE calculation is understood to be preferable and progressively larger areas are more worrisome". In the discussion the thresholds for "unsatisfactory visual comfort" (ASE > 10\%), "neutral / nominally acceptable" (ASE < 7\%) and "clearly acceptable" (ASE < 3\%) are mentioned.

\section{Analysis of the standard}

The standard IES LM-83-12 defines metrics to evaluate two main aspects of the daylighting performance of buildings. Both methods are based on annual evaluations (i.e. simulations) using climate data for the investigated location. With this, the methods account for local climatic conditions as well as building or façade orientations.

A main advantage of the metrics SDA and ASE is their common basis of horizontal work plane illuminances. These values can efficiently and accurately be calculated by today's lighting simulation software systems.

The ASE is used to evaluate the potential for visual discomfort. Using a metric based on horizontal illuminance values can only be a rough estimation of lighting effects that are caused by luminance in the field of view as seen from the - usually vertical - receiving surface mimicking the human eye.

The LEED v.4 certification scheme has adopted the SDA and ASE metrics as calculation options to perform the assessment of daylight in buildings. As the LEED certification scheme is applied worldwide, the IEA LM-83-12 standard is of international relevance.

As daylight related standard, the IES-LM-83-12 is only relevant for light transmitting SBEs. To perform well with respect to the standard, SBE systems should be able to provide enough daylight while simultaneously restricting the direct sun penetration. This is a major challenge for the development of new SBEs. 


\subsection{Ventilation}

\section{EN 13141-7}

\section{Short description of the standard}

This standard, with the title "Ventilation for buildings - Performance testing of components/products for residential ventilation - part 7: Performance testing of a mechanical supply and exhaust ventilation units (including heat recovery) for mechanical ventilation systems intended for single family dwellings" describes the requirements for the performance testing of mechanical ventilation units.

\section{Analysis of the standard}

The standard defines requirements for the testing of mechanical ventilation units regarding:

- $\quad$ aerodynamic characteristics: leakages, air flow/pressure curve

- thermal characteristics: temperature and humidity ratios on the supply air side (obligation) and on the exhaust air side after the heat exchanger (option)

- acoustic characteristics: noise radiated through the casing of the unit, sound power level in duct connections

- $\quad$ electric power input

Regarding the aerodynamic, acoustic and electric characteristics, there are no obvious problems.

However, the operating conditions for the test of the thermal characteristics determine that the ambient temperature of the unit has to be the same as the extract air temperature $( \pm 1 \mathrm{~K})$ - if the ventilation unit is situated in the façade this requirement is not fulfilled in real conditions. Nevertheless, the test of the façade integrated ventilation unit can be done according to EN 13141-7, with the hint that the achieved test results can be different from the results under real operation conditions. If the ventilation in the SBE is much colder or warmer than the exhaust air, then the efficiency of the heat recovery changes accordingly and different from the performance calculated based on the EN 13141-7 tests.

\subsection{Heat Pumps}

\section{EN 14511-2}

This European Standard, with the title "Air conditioners, liquid chilling packages and heat pumps with electrically driven compressors for space heating and cooling - part 2: test conditions", specifies the test conditions for the rating of air conditioners, liquid chilling packages and heat pumps, using either air, water or brine as heat transfer media, with electrically driven compressors when used for space heating and/or cooling. It also specifies the conditions for which performance data shall be declared for single duct and double duct units for compliance to the Ecodesign Regulation 206/2012 and Energy Labelling Regulation 626/2011.

Depending on the installation site of the heat pump the performance test has to be conducted according to defined ambient conditions.

The ambient test conditions for heat pumps, which are designed to be situated inside the building, define the drybulb temperature as measured variable with inlet temperatures between $15^{\circ} \mathrm{C}$ and $30^{\circ} \mathrm{C}$

Exceptions are water/air- and soil/air heat pumps without ports for air inlet and outlet as well as air/air heat pumps without ports on the outside air inlet and outlet. In these cases also the wet-bulb temperature is a measured variable and the inlet temperatures have to be as in the standard defined.

The ambient test conditions for heat pumps, which are designed to be situated outside the building, define the drybulb temperature as measured variable with values between $15^{\circ} \mathrm{C}$ and $30^{\circ} \mathrm{C}$ for water/water- and soil/water heat pumps operating in cooling mode and between $0^{\circ} \mathrm{C}$ and $7^{\circ} \mathrm{C}$ if the heat pump is operating in heating mode.

For air/water units, water/air- and soil/air heat pumps without a port for the air inlet and air/air units with ports on the inside air inlet and air outlet the wet-bulb temperature is an additional measured variable and the tested inlet temperatures depending on the system and defined in the standard.

Furthermore the European Standard EN 14511-2 defines the rating conditions for the different designs and the different types (air/air, water/air, soil/air, water/water, soil/water etc.). 
The test conditions for the rating of air conditioners, liquid chilling packages and heat pumps include therefore the ambient conditions depending of the installation site and the rating conditions, which are defined depending on the design and type of the unit.

\section{EN 16147}

\section{Short description of the standard}

Performance test of boiler heat pumps are made in accordance with EN 16147 "Heat pumps with electrically driven compressors - Testing and requirements for marking of domestic hot water units".

It includes the determination of the following characteristics:

- heating up time, th

- coefficient of performance (COPDHW),

- standby power input, Pes

- reference hot water temperature, $\theta^{\prime} \mathrm{WH}$

- maximum quantity of usable hot water, $\mathrm{Vm}$

Heat pumps used to generate hot water will be measured to determine the COP based on the following test sequences:

- A: heating up period

- B: stand by losses

- C: Determination of the COP for a given tapping cycle

- D: Determination of the reference hot water temperature and the maximum quantity of usable hot water

- $\mathrm{E}$ : Determination of the applicable temperature range

- F: security tests

Performance testing shall be performed for one of 5 tapping cycles $(S, M, L, X L, X X L)$ and the test conditions given in the table in the standard.

The coefficient of performance (COP) is determined by one of the following air temperatures. The following requirement apply for energy labelling:

- Indoor Air temperature $15^{\circ} \mathrm{C}: \mathrm{COP} \geq 2.9$

- Outdoor Air temperature $7^{\circ} \mathrm{C}: \mathrm{COP} \geq 2.9$

- Exhaust Air temperature $20^{\circ} \mathrm{C}$ : $\mathrm{COP} \geq 3.2$

Temperature of cold water is $10^{\circ} \mathrm{C}$. Warm water volume flow is 4 or $10 \mathrm{l} / \mathrm{min}$, depending on the tapping type. An air source heat pump is operating in a transient regime due to defrosting.

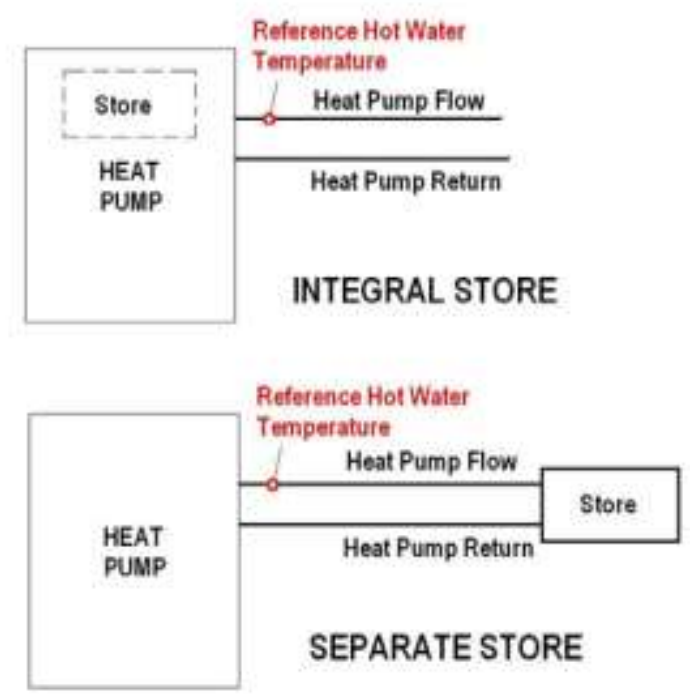

Figure 1. Identifying the store type according to the DEAP Heat Pump Methodology².

\footnotetext{
2 https://www.seai.ie/resources/publications/Heat_Pump_Guidance_2016.pdf
} 
Storage losses are determined at an ambient temperature of $20^{\circ} \mathrm{C}$ in case of ambient air heat pumps $\left(7^{\circ} \mathrm{C}\right.$ source temperature) or extract air heat pumps (and $15^{\circ} \mathrm{C}$ for indoor air heat pump (source temperature $15^{\circ} \mathrm{C}$ ).

\section{Analysis of the standard}

Heat pumps, executed as compact heat pumps, can be located inside or outside the building. Depending on the requirements of the user, one or the other installation can be more suitable. In both cases the entire heat pump (including evaporator and condenser) is located inside or outside. Most manufacturers offer both types.

In contrast to that, heat pumps can also be designed as split units, where only the evaporator is located outside. The cooling circuit then goes from the evaporator to the condenser unit, which is located inside the building.

In case of a façade integrated outdoor unit it might be combined with fresh air supply for the mechanical ventilation with heat recovery and exhaust air, which could serve as a further source for the evaporator.

For the condenser of the boiler heat pump, different hydraulic configurations exist:

- external mantel (around the cylindrical store)

- internal mantel (inside a cylindrical or cuboid shaped store)

- external plate with additional circulation pump (for all types of store design)

The following limits or obstacles could appear for SBE with integrated heat pumps and with regard to EN 16147 and EN 14511-2:

- If the outdoor unit of a split type heat pump is integrated into the façade, the EN 16147 and the EN 14511-2 apply without limit.

- If the DHW or buffer storage of the boiler HP is integrated in the façade, the "ambient temperature" of the storage is not homogeneous, but influenced by the temperatures of the exterior and of the interior of the building and the insulation between the storage and the exterior and the interior of the building.

- A hot water recovery system is not considered in EN 16147.

- Combined ambient and exhaust air as source for the evaporator is not considered in the standard.

\subsection{Fire safety}

EN 13501-1 and -5 are important standards regarding fire safety. They refer to EN 13823, ISO 11925-2, ISO 1182 and ISO 1716. Therefore, these standards are presented and analysed first, followed by an analysis of EN 13501 1 and -5 . However, it is important to keep in mind that many fire regulations may refer to EN 13823, ISO 11925-2, ISO 1182 and ISO 1716 in a different way than EN 13501-1, and -5 and that there are many other standards for fire safety which cannot be analysed by this report and which are nevertheless relevant for solar building envelopes.

\section{EN 13823}

\section{Short description of the standard}

The standard is titled "The Reaction to Fire Tests for Building Products", it specifies the fire test method and the test facility arrangements to be applied to building construction products excluding floorings when they are exposed to a thermal attack by a single burning item (SBI).

\section{Analysis of the standard}

The standard requires a typical test specimen to be a corner piece of two wings. The long wing is $1000 \mathrm{~mm}$ wide and $1500 \mathrm{~mm}$ high and the short wing is $495 \mathrm{~mm}$ wide and $1500 \mathrm{~mm}$ high. Both have a maximum thickness of 200 $\mathrm{mm}$.

Compared to the version of 2002, the version of 2010 includes that for facade elements that are larger than this sample size, the sample should be cut to that the original sample corners are close to the burner. There are also rules how to place joints and facade elements which are not flat. Therefore, only thinner SBE elements can be measured according to this standard.

The only difficulty may be large SBE which have a different fire behaviour when they are cut. It is also not clear whether the cut cross section is allowed to be sealed reasonably. This is especially important for SBE elements like tall BIST collectors which fire properties are expected to change with an open compared to a closed cut at the top. 


\section{ISO 11925-2}

\section{Short description of the standard}

The standard is titled "Reaction to Fire Tests - Ignitability of building products subjected to direct impingement of flame". The standard specifics the fire test method to determine the ignitability of building products by direct small flame impingement under zero impressed irradiance using specimens tested in the vertical orientation.

\section{Analysis of the standard}

Most SBE elements need to be cut to fit the sample size. If an SBE element is thicker than $120 \mathrm{~mm}$, only the 60 $\mathrm{mm}$ facing the exterior and the $60 \mathrm{~mm}$ facing the interior will be part of this test.

SBE elements which use not-ignitable layers within these $60+60 \mathrm{~mm}$ will reach good results. SBE elements which use ignitable layers within the sample size but covered edges can be tested according to this standard. The local regulations should use the result with the covered edges for their permissions and not the unrealistic result without covered edges.

If the covered edges have a width of more than $45 \mathrm{~mm}$, then they cannot be placed in the sample width of $90 \mathrm{~mm}$ and cannot be tested according to this standard.

For SBE elements which have a frame with a depth of more than $120 \mathrm{~mm}$, it is not defined how to build the frame for the testing.

\section{ISO 1182}

\section{Short description of the standard}

The standard is titled "Reaction to Fire Tests for building and transport products - Non-combustibility test". The standard specifies a method of test for determining the non-combustibility performance, under specified conditions, of homogeneous products and substantial components of non-homogeneous products.

\section{Analysis of the standard}

The standard requires a specimen to fit in the specimen holder of size. Non-homogeneous products cannot be tested according to ISO 1182, only homogeneous materials and substantial components of non-homogenous products. A substantial component has a mass/unit area $>1 \mathrm{~kg} / \mathrm{m}^{2}$ or a thickness $\geq 1 \mathrm{~mm}$. The specimen may be solid, fray out or be a liquid-applied material like an adhesive. The standard defines no procedures for liquid materials.

Some SBE contain more than $1 \mathrm{~kg} / \mathrm{m}^{2}$ of liquid. Therefore not all of their materials can be tested. Even SBE with less than $1 \mathrm{~kg} / \mathrm{m}^{2}$ of liquids often involve tubes with liquids which are thicker than $1 \mathrm{~mm}$. Even for heat-pipes with very little fluid within a closed pipe, the fluid could be considered as thicker than $1 \mathrm{~mm}$. Therefore, there is a substantial risk that SBE cannot be fully measured according to ISO 1182.

Even if a procedure to measure fluids would be added, SBE may reach a very low fire safety class although their burnable fluids may be well-protected from fire.

\section{ISO 1716}

\section{Short description of the standard}

The standard is titled "Reaction to Fire Tests for products - Determination of gross heat of combustion (calorific value). The standard specifies a method for the determination of the gross heat of combustion ( $\left.Q_{\mathrm{PCS}}\right)$ of products at constant volume in a bomb calorimeter.

In this test, a test specimen of specified mass is burned under standardized conditions, at constant volume, in an atmosphere of oxygen, in a bomb calorimeter calibrated by combustion of certified benzoic acid. The heat of combustion determined under these conditions is calculated based on the observed temperature rise, taking account of heat loss and the latent heat of vaporization of water. This is a test method for determining an absolute value of the heat of combustion for a product and it does not consider any inherent variability of the product. 


\section{Analysis of the standard}

SBE are often made of several materials. ISO 1716 provides a way to determine the gross heat of combustion for non-homogeneous products. However, the standard discusses only non-homogeneous products which consist of layers of materials.

The standard does not specify a minimum thickness or weight per area for a material. This can be a barrier for SBE that consists of a large number of materials, because the tests are then very expensive. The standard does not define whether for example a coated glass pane needs separate tests for the glass and the materials of its coating.

The resulting value for the gross heat of combustion can be very high when burnable materials are used in a SBE component. The calculation method does not reflect whether the burnable material is well-protected from fire.

\section{EN 13501-1}

\section{Short description of the standard}

The standard provides the fire classification of construction products and building elements using data from reaction to fire tests. It includes classes of reaction to fire performance for construction products, floorings and linear pipe thermal insulation products (maximum outer insulation diameter of $300 \mathrm{~mm}$ and not intended for use with cylindrical ducts).

Under the EN13501-1 standard, a fire classification is obtained by performing tests or extended application processes predicting test results for a variation of a product property and, in both cases, considered in relation to the end use application. A product needs then to be prepared, conditioned, possibly mounted, positioned and oriented in relevance to the relevant test method and the intended use of application. The five test methods used for classifications are: 1) Non-combustibility test (EN ISO 1182) to identify products non-significantly contributing to fire (class $A 1$ and $A 2$ ) ,2) Heat of combustion test (EN ISO 1716) determining the total heat release of a product completely burning (relevant to class A1 and A2), 3) Single burning item test (EN 13823) evaluating the potential contribution to the development of a fire by a non-flooring product with a fire located in a room corner near that product (mostly relevant for classes A2 to D), 4) Ignitability test (EN ISO 11925-2) evaluating the ignitability of a product under exposure to a small flame (relevant for class $B$ to $E$ ) and 5) Determination of the burning behaviour of floorings, using a radiant heat source (EN ISO 9239-1) (relevant to flooring class A2 to D). A classification is obtained by calculating the mean value of continuous parameters, such as temperature rise, mass loss, fire growth rate index, and smoke growth rate index, over a specific number of tests. As illustrated in Figure 2, even though the results may cover different classes, if the mean value $m$ ' is within the range of the expected class the tested product obtains this class. If the mean value is out of the expected range then an additional two tests can be performed. The highest and lowest values from the complete set of tests are then discarded to obtain the mean value that is then determining the class of that product. While such probabilistic and statistical approach provide the tendency on the fire behaviour of a product, it also means that such product may well be over-classified and fail to perform under the upper class that was attributed.

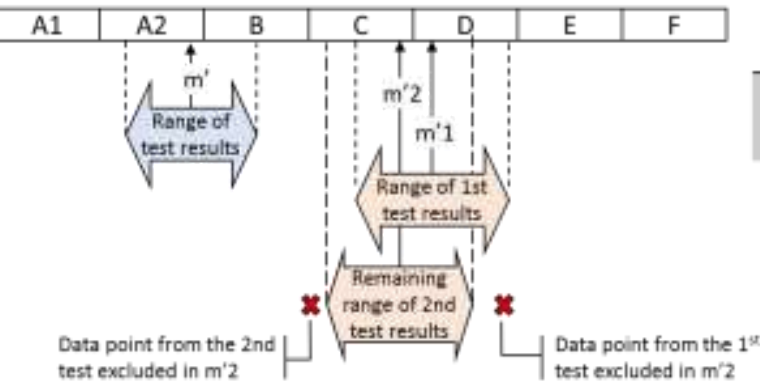

\begin{tabular}{|c|c|c|}
\hline $\begin{array}{l}\text { Envisaged } \\
\text { Class }\end{array}$ & Example of Test results & Class obtained \\
\hline A2 & $\begin{array}{l}\text { Set of results range from class } A 2 \text { to } B \text { but } m^{\prime} \text { is } \\
\text { included into } A 2 \text { definition }\end{array}$ & $\begin{array}{l}\text { A2 while tests still } \\
\text { show class B results }\end{array}$ \\
\hline C & $\begin{array}{l}\text { The first set of results gives m' } 1 \text { and a Class } D \text { that } \\
\text { is lower than the expected class. Another } 2 \text { data } \\
\text { points are measured and added to the previous. } \\
\text { The highest and lowest data points are discarded to } \\
\text { obtain m' } 2 \text { which is now within class } C \text {. }\end{array}$ & $\begin{array}{l}\text { C while tests still } \\
\text { show class D results }\end{array}$ \\
\hline
\end{tabular}

Figure 2. Schematic drawing of the test results and the corresponding fire class.

For compliance to lateral flame spread, flame spread and flaming droplets/particles, a classification is obtained according to the occurrence of a non-compliant parameter result. If all test results are within parameters then the product is "compliant". If more than one result is out of boundaries then the product is "non-compliant". However, if only one result is non-compliant then an additional two tests are performed and the "compliant" class is given if both tests are compliant. Once again, this means that even though a product may be "compliant" it may well have been shown to be "non-compliant" during the tests. 
Figure 3 presents an overview of the fire classes according to EN 13501-1.

\begin{tabular}{|c|c|c|c|}
\hline Class & Test method(s) & Classification criteria & Additional classification \\
\hline \multirow[t]{2}{*}{ A1 } & $\begin{array}{l}\text { prEN ISO } 1182(1) \\
\text { and }\end{array}$ & $\begin{array}{l}\Delta T \leq 30^{\circ} \mathrm{C} ; \text { and } \\
\Delta m \leq 50 \% ; \text { and } \\
t=0 \text { (i.e. no sustained flaming) }\end{array}$ & $\cdot$ \\
\hline & prEN ISO 1716 & $\begin{array}{l}P C S \leq 2,0 \mathrm{MJ} / \mathrm{kg}\left({ }^{1}\right) \text { and } \\
P C S \leq 2,0 \mathrm{MJ} / \mathrm{kg}^{2}\left({ }^{2}\right)\left({ }^{2}\right) \text { and } \\
P C S \leq 1,4 \mathrm{MJ} / \mathrm{m}^{2}\left({ }^{3}\right) \text { and } \\
P C S \leq 2,0 \mathrm{MJ} / \mathrm{kg}\left({ }^{4}\right)\end{array}$ & $\cdot$ \\
\hline \multirow[t]{3}{*}{ A2 } & $\begin{array}{l}\text { prEN ISO } 1182\left({ }^{1}\right) \\
\text { or }\end{array}$ & $\begin{array}{l}\Delta T \leq 50^{\circ} \mathrm{C} \text {; and } \\
\Delta m \leq 50 \% \text {; and } \\
t \leq 20 \mathrm{~s}\end{array}$ & $\cdot$ \\
\hline & $\begin{array}{l}\text { prEN ISO } 1716 \\
\text { and }\end{array}$ & $\begin{array}{l}P C S \leq 3,0 \mathrm{MJ} / \mathrm{kg}^{(1)} \text { and } \\
P C S \leq 4,0 \mathrm{MJ} / \mathrm{m}^{2}\left({ }^{2}\right) \text { and } \\
P C S \leq 4,0 \mathrm{MJ} / \mathrm{m}^{2}\left({ }^{3}\right) \text { and } \\
\left.P C S \leq 3,0 \mathrm{MJ} / \mathrm{kg}^{4}\right)\end{array}$ & $\cdot$ \\
\hline & EN 13823 & $\begin{array}{l}\text { FIGRA } \leq 120 \mathrm{~W} / \mathrm{s} \text { and } \\
\text { LFS }<\text { edge of specimen and } \\
T H R_{800 s} \leq 7,5 \mathrm{MJ}\end{array}$ & $\begin{array}{l}\text { Smoke production }\left({ }^{5}\right) \text { and } \\
\text { Flaming droplets/particles }\left({ }^{6}\right)\end{array}$ \\
\hline \multirow[t]{2}{*}{$\bar{B}$} & $\begin{array}{l}\text { EN } 13823 \\
\text { and }\end{array}$ & $\begin{array}{l}\text { FIGRA } \leq 120 \mathrm{~W} / \mathrm{s} \text { and } \\
\text { LFS }<\text { edge of specimen and } \\
\text { THR } 3000 \mathrm{~s} \leq 7,5 \mathrm{MJ}\end{array}$ & \multirow[t]{2}{*}{$\begin{array}{l}\text { Smoke production }\left({ }^{5}\right) \text { and } \\
\text { Flaming droplets/particles }\left({ }^{6}\right)\end{array}$} \\
\hline & $\begin{array}{l}\text { prEN ISO } 11925-2\left({ }^{8}\right): \\
\text { Exposure }=30 \mathrm{~s}\end{array}$ & Fs $\leq 150 \mathrm{~mm}$ within $60 \mathrm{~s}$ & \\
\hline \multirow[t]{2}{*}{$\overline{\mathbf{C}}$} & $\begin{array}{l}\text { EN } 13823 \\
\text { and }\end{array}$ & $\begin{array}{l}\text { FIGRA } \leq 250 \mathrm{~W} / \mathrm{s} \text { and } \\
\text { LFS }<\text { edge of specimen and } \\
T H R_{600 \mathrm{~s}} \leq 15 \mathrm{MJ}\end{array}$ & \multirow[t]{2}{*}{$\begin{array}{l}\text { Smoke production }\left({ }^{5}\right) \text { and } \\
\text { Flaming droplets/particles }\left({ }^{6}\right)\end{array}$} \\
\hline & $\begin{array}{l}\text { prEN ISO } 11925-2\left({ }^{8}\right): \\
\text { Exposure }=30 \mathrm{~s}\end{array}$ & $F_{s} \leq 150 \mathrm{~mm}$ within $60 \mathrm{~s}$ & \\
\hline \multirow[t]{2}{*}{$\bar{D}$} & $\begin{array}{l}\text { EN } 13823 \\
\text { and }\end{array}$ & FIGRA $\leq 750 \mathrm{~W} / \mathrm{s}$ & \multirow[t]{2}{*}{$\begin{array}{l}\text { Smoke production }\left({ }^{5}\right) \text { and } \\
\text { Flaming droplets/particles }(6)\end{array}$} \\
\hline & $\begin{array}{l}\text { prEN ISO } 11925-2\left({ }^{8}\right): \\
\text { Exposure }=30 \mathrm{~s}\end{array}$ & Fs $\leq 150 \mathrm{~mm}$ within $60 \mathrm{~s}$ & \\
\hline $\bar{E}$ & $\begin{array}{l}\text { prEN ISO } 11925-2\left({ }^{8}\right): \\
\text { Exposure }=15 \mathrm{~s}\end{array}$ & $F_{s} \leq 150 \mathrm{~mm}$ within $20 \mathrm{~s}$ & Flaming droplets/particles(7) \\
\hline $\bar{F}$ & \multicolumn{3}{|c|}{ No performance determined } \\
\hline
\end{tabular}

Figure 3. Classes of reaction to fire performance for construction products excluding floorings [6].

\section{Analysis of the standard}

Every SBE reaches at least fire class F. This means that it is typically allowed to manufacture and sell even SBE with poor fire behaviour. However, only few regulations will allow such SBE to be installed which means the market for such SBE is very limited.

To reach fire class $E$ and $D$, the flame is not allowed to reach a height of $150 \mathrm{~mm}$ within a certain timeframe. The flame is targeted at the outer surface of the SBE. If the edge of the SBE can be exposed to flames in the planned installations, the flame is also targeted at the bottom edge of the SBE. In this case, the edge has to be similar to the edge of the real SBE installation. For fire class D, a fire growth rate FIGRA of less than $250 \mathrm{~W} / \mathrm{s}$ is necessary from a test according to EN 13823. If a SBE element is higher than $1.5 \mathrm{~m}$, it is not clear whether the sample can be cut at this height and if the cut can be closed.

For fire class $\mathrm{C}$ and $\mathrm{B}$, the lateral flame spread is not allowed to reach the edges of the sample and the total heat release within 600 seconds according to EN 13823 needs to stay below certain values.

The EN 13823 criteria of fire class B apply for class A2, too. The gross heat of combustion needs to stay below certain values at tests according to ISO 1716. These values differ for substantial components, external and internal non-substantial components and the product as a whole. EN 13501-1 defines a non-substantial component as a material that does not constitute a significant part of a non-homogeneous product. A layer with a mass/unit area below $1 \mathrm{~kg} / \mathrm{m}^{2}$ and a thickness below $1 \mathrm{~mm}$ is considered to be a non-substantial component. It is not clear when a component which is not a layer can be considered as non-substantial. For example if heat pipes with an organic fluid are used within a SBE, it maybe receive a bad fire class although the amount of the fluid is small and although the fluid is well capsulated within a pipe.

Additionally, fire class $\mathrm{A} 1$ and $\mathrm{A} 2$ require tests according to ISO 1182 and that either the mass reduction and maximum temperature increase stay below certain values or that there are no self-sustained flames for A1 or less 
than 20 seconds of flames for A2. It is not clear how to test liquid components according to ISO 1182 . ISO 1182 uses a similar definition of non-substantial as EN 13501-1 and the tests are only required for substantial components. As for the above-mentioned heat pipe with organic fluid, it is not clear whether such a fluid has to be considered as substantial, if it has a thickness of more than $1 \mathrm{~mm}$, but only at specific locations. Many regulations have high requirements regarding fire safety. Therefore, it is important to clarify which technologies can be applied in almost all markets and which are limited to a smaller market.

\section{EN 13501-5}

\section{Short description of the standard}

The standard classifies the fire performance of roofs/roof coverings exposed to external fire based on the four test methods given in CEN/TS 1187:2012 corresponding to different fire hazard scenarios. It includes aspects as external and internal fire spread, external and internal damage, fire penetration and the occurrence of flaming droplets or debris.

The four tests in the standard envisaged with the field of application of the classification are:

Test 1: Method with burning brands. In this test, four specimens are tested out on a variety of combinations of joints in the weathering and insulation layers. Five standard supporting decks are specified in CEN/TS 1187 and apply to three fields of applications:

- Non profiled continuous deck (4 types defined): 1) Wooden continuous deck (>=16 mm) with gap not exceeding $0,5 \mathrm{~mm}, 2$ ) Wooden continuous deck with gap not exceeding $5 \mathrm{~mm}, 3$ ) Continuous noncombustible board of minimum $10 \mathrm{~mm}$ thickness without gaps, 4) Non-combustible board of minimum $10 \mathrm{~mm}$ thickness with gaps not exceeding $5 \mathrm{~mm}$

- Trapezoidal profiled not perforated steel deck

- Roof without a continuous deck

For any other field of application, the actual intended deck needs to be tested. Roof pitch tested at $15^{\circ}$ apply to roofs with pitches $<20^{\circ}$ and test results obtained at $45^{\circ}$ apply to roofs with pitches $>20^{\circ}$.

Test 2: Method with burning brands and wind. Here, four standard substrates are defined for non-combustible and combustible fields of applications and three test specimens are tested at 2 wind speeds.

Test 3: Method with burning brands, wind and supplementary radiant heat. The same five standard decks are used for the same three fields of applications as in Test 1 but the tested pitch is either $5^{\circ}$ or $30^{\circ}$ applied to roof pitch up to $70^{\circ}$ and only two test specimens are tested.

Test 4: Two-stage method incorporating burning brands, wind and supplementary radiant heat. Under this fourth test, considering the supporting structure, only the actual deck with its supporting structure can be tested with a pitch of either $0^{\circ}$ or $45^{\circ}$ applied to roof pitch up to $70^{\circ}$. One test specimen is tested in the preliminary test (Stage 1) and three test specimens are tested in the penetration test with at least one specimen containing examples of the joint details in each layer of the roof system.

\section{Analysis of the standard}

Roof coverings englobe roof materials and cladding elements and, by that definition, all roof building integrated (BI) systems such as photovoltaic (BIPV) or solar thermal (BIST) systems should be tested under that standard or generally tested under EN 13501-1.

Regarding fire test standard used for BIPV and BIST, electrical codes such as the IEC 60364-7-712, NFPA 70 and the CEI 64-8 well address the fire risk due to overload and short circuit of electrical power plants including BIPV. However, as it already appeared under the EN 13501-1 standard, roofs with elements of a solar building envelope that are added post-construction of the building would not be tested under that standard. 


\section{Conclusions}

This report is the result of the work of international experts within Subtask B of IEA SHC Task 56. It assesses the applicability of the most relevant standards to SBE technologies. Recent standards are specific of SBE, such as the EN 50583 for BIPV systems and the EN 17037 for daylighting. Other standards have been designed for nonbuilding integrated components, such as the ISO 9806 for thermal collectors, the EN 13141-7 for ventilation units and the EN 16147 and EN 14511-2 for heat pumps.

Although some standards can easily be applied to SBE, in many cases, this is not the case. Current testing methods are established for standard, non-building integrated products. The results of the analysis show that the building integration of many technologies poses additional challenges, which are not adequately captured by the standards. One consequence is that testing and certifying some SBE technologies can be more expensive than conventional products. Another consequence is that the benefits of such technologies with respect to conventional ones are not captured by standardized testing methods. As a result, for some technologies such as BIST, current standards present a barrier for the market penetration.

One recommendation for technical committees that deal either with technical building systems or with building envelopes is that they analyse if barriers for SBE exist and how they could be removed. For example, the ISO 9806 standard could be easily extended with a section on building-integrated solar thermal collectors. Such a section could include a calculation procedure for collector efficiency under the consideration of the energy flux into the building.

Another recommendation, in this case for legislative authorities, is to consider the special needs of SBE technologies, as important technologies for reducing carbon emissions, and to adapt their requirements of manufacturing and installation accordingly.

It is also important to note that, given that standards and regulations have long intervals between updates, it is crucial not to consider available products only, but also technologies that are under investigation, as well as different technological options. 


\section{Acknowledgements}

This work was partially funded by the German Federal Ministry for Economic Affairs and Energy (BMWi), based on a decision by the German Bundestag. 


\section{References}

[1] C. Maurer, C. Cappel, T.E. Kuhn, Progress in building-integrated solar thermal systems, in: Elsevier (Ed.), Progress in Solar Energy, 2017, pp. 158-186, http://publica.fraunhofer.de/documents/N-456045.html, https://doi.org/10.1016/j.solener.2017.05.065.

[2] M. Knoop, O. Stefani, B.Bueno, B. Matusiak, R. Hobday, A Wirz-Justice, K.Mtiny, T. Kanterman, M. P. J. Aarts, N. Zemmouri, S. Applet and B. Norton, Daylight: What makes the difference? Lighting Research and Technology 0, 2019, pp. 1-20. 